\title{
Analysis of Japanese encephalitis epidemic in western Nepal in 1997
}

\author{
T. AKIBA ${ }^{1 *}$, K. OSAKA ${ }^{2}$, S. TANG ${ }^{3}$, M. NAKAYAMA ${ }^{4}$, A. YAMAMOTO ${ }^{4}$, \\ I. KURANE ${ }^{4}$, N. OKABE ${ }^{2}$ AND T. UMENAI ${ }^{5}$ \\ ${ }^{1}$ Japan International Cooperation Agency (JICA) Project Office, Human Resource Development Division/ \\ Ministry of Health, Accra, Ghana \\ ${ }^{2}$ Infectious Disease Surveillance Center, National Institute of Infectious Diseases, Tokyo, Japan \\ ${ }^{3}$ Liverpool School of Tropical Medicine, Pembroke Place, Liverpool, UK \\ ${ }^{4}$ Department of Virology I, National Institute of Infectious Diseases, Tokyo, Japan \\ ${ }^{5}$ Department of Health Policy and Planning, The University of Tokyo
}

(Accepted 12 July 2000)

\section{SUMMARY}

We conducted an epidemiological study of a Japanese encephalitis (JE) outbreak in the southwestern part of Nepal in 1997. A high density of JE infections was found and it was estimated that $27.9 \%$ the total population were infected with JE virus in the study area. The fatality rate was $13.2 \%$ and there was no difference in the fatality rate between males and females over 5 years old. However, the case fatality rate was $2 \cdot 1$ times higher in females than in males $(14.6 \%$ vs. $6.9 \%)$ among children under 5 years of age. Fifty-three blood samples were collected from suspected JE cases during the epidemic period in 1998. Findings for JE specific IgM revealed that clinical diagnoses of JE were serologically confirmed in an average $78 \%(70-93 \%)$ of patients in three collaborating hospitals. These studies demonstrated that JE was highly prevalent in the area and clinical diagnoses were reliable. Effective preventive measures should be taken against this vaccine-preventable disease.

\section{INTRODUCTION}

Japanese encephalitis (JE) is a mosquito-borne viral disease prevalent in Southeast Asia and the Indian sub-continent. Japanese encephalitis virus (JEV) is transmitted by infected mosquitoes with pigs (or birds) as amplifiers. Fifteen to $25 \%$ of JE cases are fatal and approximately one third recover with mild to severe neurological sequelae $[1,2]$. The outbreaks of JE were recently observed in Australia [3] and on the island of Saipan [4]. Although countries including Japan and Korea have already controlled JE through

* Author for Correspondence: Japan International Cooperation Agency (JICA) Project Office, Human Resource Development Division/Ministry of Health, P.O. Box M44, Accra, Ghana. extensive JE vaccine programmes, JE still heavily affects persons living in developing countries in the endemic areas. Major factors that make the control of JE difficult are: (i) difficulty in controlling JEV vectors (mainly Curex tritaeniorryncus) [5], (ii) increased number of pigs (JEV amplifier) are an important source of income in the community, (iii) unaffordable price of currently available JE vaccine for general use (\$2.16-3.68/dose) [6], (iv) absence of specific treatment for JE [7] and (v) expansion of mosquito breeding sites by national development scheme (e.g. irrigation for rice fields, dam constructions).

Nepal had very few encephalitis cases in the early 1970s [8]. Confirmed JE cases were first reported in 1978 [9]. Since then, the number of cases has been 
increasing. Although great efforts have been made in Nepal, JE control has not been successful due to the above-mentioned reasons. In 1997, 2403 JE cases were reported with 335 fatal cases and this was the worst JE epidemic in the history of Nepal [8]. The JE situation in one area in the western part of Nepal was reported as a disaster and collective help was provided by the international organizations [10]. The present study is an epidemiological investigation of the JE outbreak in 1997. The study was performed to further delineate the JE epidemic and to evaluate the reliability of clinical diagnosis of JE in the study area.

\section{METHODS}

\section{Selection of study sites}

According to past epidemiological studies on JE in Nepal, the JE incidence is restricted to the Terai region, which is a narrow belt with an altitude of about 100-600 metres along the boundary with India $[11,12]$. High temperature (the average maximum day temperature from June to September: $32 \cdot 3{ }^{\circ} \mathrm{C}$ ) [13], high humidity (the average precipitation from June to September: $1498 \mathrm{~mm} / \mathrm{month}$ ) [13] and vast rice fields in the Terai could be main reasons why JE outbreaks were reported in this region. The JE outbreak in 1997 resulted in 2403 cases in the entire country and $80.6 \%$ of the cases (1939 cases) were concentrated in the western part of The Terai [8]. As shown in Figure 1, three districts, i.e. Banke, Bardia and Kailali, are located in highly endemic region. Therefore, these three districts were selected for the present study.

\section{Subjects for epidemiological study}

Information on JE cases was collected in the three epidemic districts, Banke, Bardia and Kailali in 1997. The study base was set at Nepalgunj, the largest city in the western part of Nepal. Six health facilities were involved in the study, and a total of 1819 recorded JE cases were reviewed. Hospital records contained age, sex, admission and discharged dates, and address of patients. According to the physicians in the hospitals, JE cases were diagnosed according to the criteria: (1) clinical symptoms including high fever, altered sensory, neck rigidity and unconsciousness, (2) exclusion of malaria, bacterial meningitis and typhoid fever through the microscopic observation of thick blood film, CSF test and Wider test and (3) follow up for

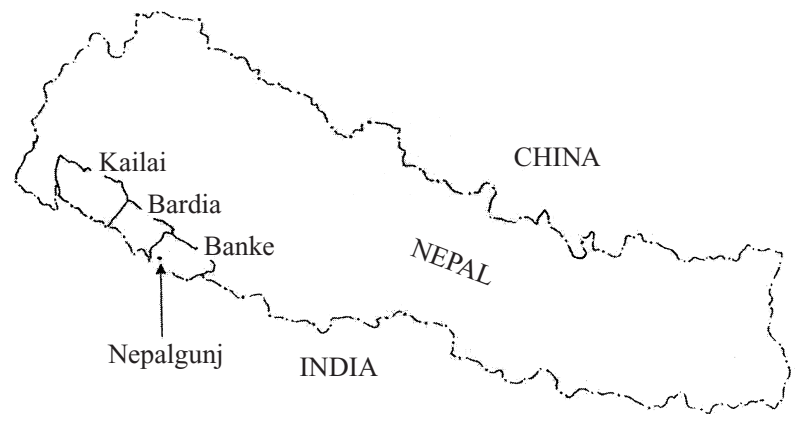

Fig. 1. Map of the study area, Banke, Bradia and Kailai districts were selected for the study. The study base was set at Nepalgunj, the largest city in the western part of Nepal.

several days. There were no JE-specific laboratory tests available in this region. It was noted that some hospital records were incomplete and lacked information on age or address, and that physicians did not always follow the standards for the clinical diagnosis of JE.

\section{Serological tests for JE diagnosed cases}

Blood samples were collected from inpatients diagnosed with $\mathrm{JE}$ in the three hospitals in Banke and Bardia districts. The blood specimens were collected from 15 August to 10 September 1998. A consent form in the local language was presented and the patient's or guardian's agreement to use the blood specimens for JE study was obtained. Blood was taken by laboratory technicians or pathologists in each hospital. The name, age, sex, address, clinical signs and performed clinical tests were recorded on the report form. The samples were kept in the ice compartment of an refrigerator until they were sent to the National Institute of Infectious Diseases, Tokyo, Japan. Detection of JEV specific IgM was performed immediately after arrival of the samples in the Institute. IgM-ELISA was performed according to the method reported by Duermeyer and colleagues [14] with modifications. Wells of the immunoplate were sensitized with $0.1 \mathrm{ml}$ of the goat anti-human $\operatorname{IgM}$ ( $\mu$-chain specific) antibody (Cappel, PA, USA) at $2 \mu \mathrm{g} / \mathrm{ml}$ in $0.05 \mathrm{~m}$ carbonate buffer, $\mathrm{pH} 9 \cdot 6$. After $1 \mathrm{~h}$ incubation at $37^{\circ} \mathrm{C}$, wells were washed three times with PBS containing $0.05 \%$ Tween (PBS-T). Twentyfive millilitres of serially 2 -fold-diluted serum samples in PBS-T were added to wells, and incubated at $37^{\circ} \mathrm{C}$ for $1 \mathrm{~h}$. After washing three times with PBS-T, $0.05 \mathrm{ml}$ of JE antigen was added to each well and incubated at room temperature for $1 \mathrm{~h}$. The plates were washed 
three times with PBS-T, and rabbit hyperimmune serum to JEV was added and incubated at $37^{\circ} \mathrm{C}$ for $1 \mathrm{~h}$. The plates were washed three times with PBS-T, alkaline phosphatase-conjugated goat anti-rabbit IgG antibody (Cappel, PA, USA) at $5 \mu \mathrm{g} / \mathrm{ml}$ was added and incubated at $37^{\circ} \mathrm{C}$ or $1 \mathrm{~h}$. After washing, $200 \mu \mathrm{l}$ of $0.1 \% p$-nitrophenyl phosphate disodium was added and incubated for $30 \mathrm{~min}$ at $37^{\circ} \mathrm{C}$. The stop reagent, $2.5 \mathrm{M} \mathrm{H}_{2} \mathrm{SO}_{4}$ was then added and the resulting colour change was quantified at $405 \mathrm{~nm}$ wave length. JEV specific IgM titre was indicated as the highest dilution of the serum samples which provided optical density of $0 \cdot 2$ or greater $[15,16]$.

\section{Data analysis}

After the necessary amendment of original data (translation of the Nepali names and dates into the English alphabet), all patients' data were entered into an Excel 97 spreadsheet (Microsoft, USA). The analysis was conducted by filter functions and statistical programs in this software. The Epi-Info (version 6.04, CDC, Atlanta, USA) program was also used for statistical analyses. Double checks for the original data and the printout from the computer were repeatedly performed to verify data quality.

\section{JE case mapping}

JE cases were mapped in Banke, Bardia and Kailali districts. Firstly, all patients were grouped according to their VDC (Village District Committee, the rural administrative unit) name. Then, the JE incidence (case/1000) was calculated in each VDC. The estimated population was obtained from the data book 'District Public Health Office Annual Report for 1997', available at all District Public Health Offices. The map of the three districts was scanned from 'the Atlas of Population Distribution and Health Facilities' [17] by Adobe PageMaker programme and finally, the JE cases were plotted on the map.

\section{RESULTS}

\section{Total JE cases in 1997 diagnosed in Banke, Bandi and Kailali districts}

A total of 1819 JE diagnosed cases were reviewed from five hospitals and one Primary Health Care Centre in three districts. This indicates that the study
Table 1. Hospital names and number of JE diagnosed cases in 1997

\begin{tabular}{llc}
\hline \hline Hospital name & District & $\begin{array}{l}\text { No. of } \\
\text { JE cases }\end{array}$ \\
\hline Bheri Zonal Hospital & Banke & 771 \\
NMC* Hospital & Banke & 179 \\
NMC* Khohalpur Hospital & Banke & 53 \\
Bardia District Hospital & Bardia & 114 \\
Seti Zonal Hospital & Kailali & 376 \\
Tikapur PHC $\dagger$ Centre & Kailali & 336 \\
Total & & 1819 \\
\hline \hline
\end{tabular}

* NMC, Nepalgunj Medical College.

$\uparrow$ PHC, Primary Health Care.

covered $75.7 \%$ (1819 of 2403 patients) of the total JE cases reported in 1997. Bheri Zonal Hospital had the highest number of patients (771), followed by Seti Zonal Hospital (376). Although Tikapur Primary Health Care Centre was not a hospital, the third largest number of patients (336) was recorded in this centre (Table 1).

The records indicated that the JE outbreak started in the first week of August and peaked in the first week of September (2-8 September) with admission of 615 cases per week for the three districts. This outbreak ended in the last week of October after 12 weeks of duration (Fig. 2). With regards to the age distribution of JE patients, the cases peaked in children aged 5 years (129 cases) and patients under 15 years accounted for $68 \%$ of the $1819 \mathrm{JE}$ cases.

\section{Gender difference of $\mathrm{JE}$ cases}

Among 1819 JE cases, 1015 (56\%) were male and 804 $(44 \%)$ female. The gender difference was especially noticeable among children under 5 years old and male patients exceeded female by $65 \%$ (male $203 \mathrm{vs}$. female 123). On the contrary, the case fatality rate among children under 5 years of age was much higher in females than in males. Table 2 shows that the fatality rate was $2 \cdot 1$ times higher in females than in males within this age group (male $6.9 \%$ vs. female $14.6 \%$ ), although the fatality rate over 6 years of age did not differ between male and female cases (male $14 \cdot 1 \% \mathrm{vs}$. female $13.0 \%$ ).

\section{Serological study}

A total of 53 blood samples were collected from 


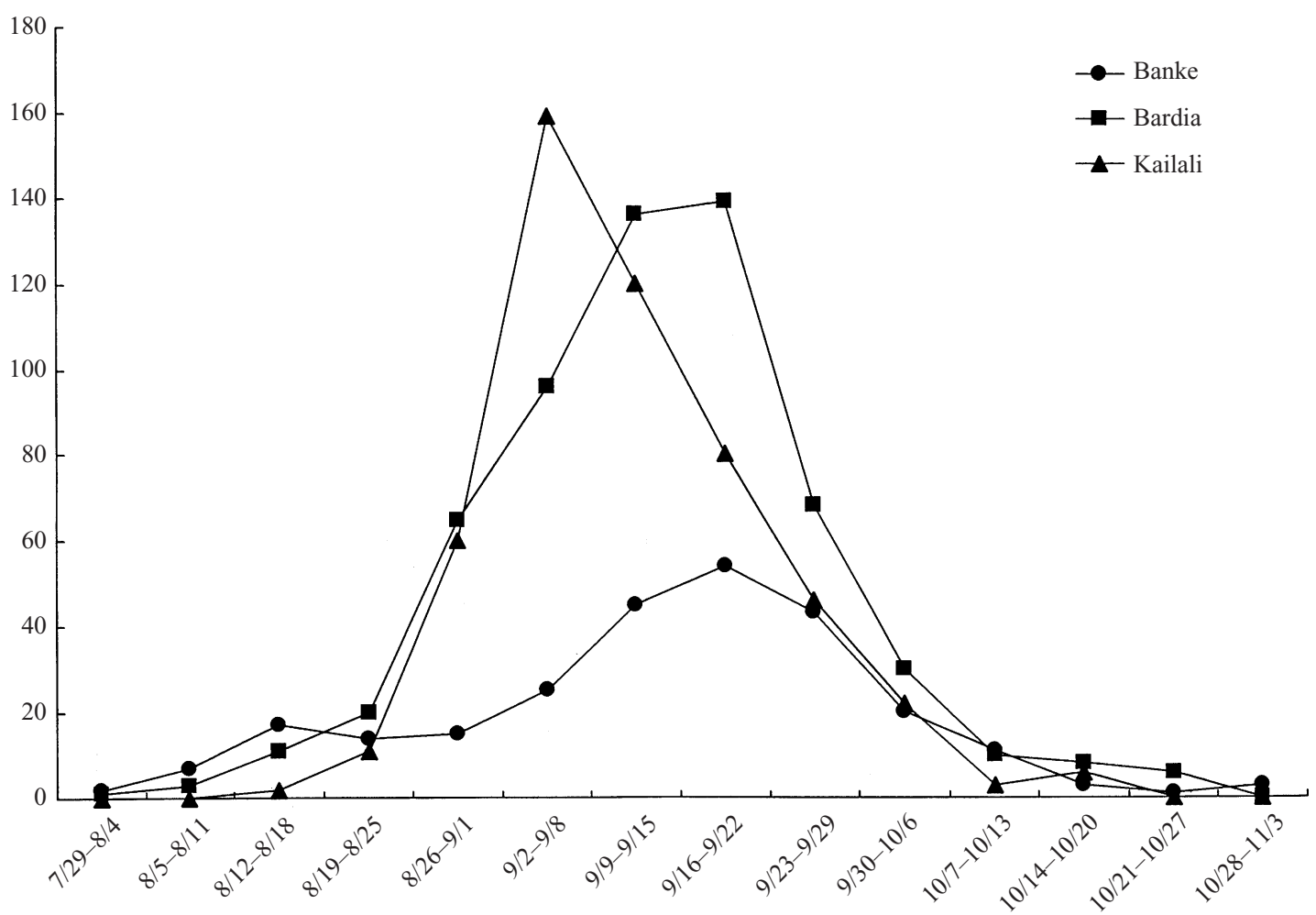

Fig. 2. Weekly incidence of JE in the three study districts. Weekly JE cases peaked in September, 1997.

Table 2. Gender difference of JE fatality rate among male and female at age groups in 1997

\begin{tabular}{|c|c|c|c|c|c|c|c|}
\hline \multirow[b]{2}{*}{$\begin{array}{l}\text { Age } \\
\text { group }\end{array}$} & \multicolumn{3}{|l|}{ Male } & \multicolumn{3}{|c|}{ Female } & \multirow[b]{2}{*}{$P$ value* } \\
\hline & Cases & Death & $\begin{array}{l}\text { Fatality } \\
\text { rate }(\%)\end{array}$ & Cases & Death & $\begin{array}{l}\text { Fatality } \\
\text { rate }(\%)\end{array}$ & \\
\hline-5 & 203 & 14 & $6 \cdot 9$ & 123 & 18 & $14 \cdot 6$ & $0.041 \dagger$ \\
\hline $6-15$ & 438 & 49 & $11 \cdot 2$ & 347 & 42 & $12 \cdot 1$ & 0.72 \\
\hline $16-$ & 270 & 56 & $20 \cdot 7$ & 251 & 36 & $14 \cdot 3$ & $0 \cdot 11$ \\
\hline Total & 911 & 119 & $13 \cdot 1$ & 721 & 96 & $13 \cdot 3$ & $0 \cdot 88$ \\
\hline
\end{tabular}

* $P$ value was calculated by $\chi^{2}$ test.

$\dagger$ Statistically significant difference $(P<0 \cdot 05)$.

clinically diagnosed JE patients in three health facilities, Nepalgunj Medical College Hospital, Bardia District Hospital, Bheri Zonal Hospital, during the study period from 15 August to 10 September 1998 (Table 3). Most of the patients had typical encephalitic signs, i.e. unconsciousness, lethargy and mental clouding. Fourteen blood samples were collected from Bardia District Hospital and 4 of these 14 cases died during the study period. The results of IgM-capture ELISA demonstrated that serologically confirmed cases among JE suspected cases in 1998 were 7/9 $(78 \%), 13 / 14(93 \%)$ and $21 / 30(70 \%)$ in Nepalgunj
Medical College Hospital, Bardia District Hospital and Bheri Zonal Hospital, respectively.

\section{JE case mapping}

The average JE incidence ratio in the three districts were 1.45 cases per 1000 . The highest incidence ratio was found in Bardia district (1.85/1000), followed by Kailali $(1 \cdot 60 / 1000)$ and Banke $(0 \cdot 82 / 1000)$. The grade of $\mathrm{JE}$ incidence ratio in three districts is shown in Table 4. The majority of VDCs in Banke had lower incidence ratio $(\leqslant 1 \cdot 0,77 \%)$. On the contrary, the 
Table 3. The sensitivity of the JE diagnosis in the study hospitals (1998)

\begin{tabular}{llll}
\hline \hline Hospital name & $\begin{array}{l}\text { No. of cases } \\
\text { diagnosed as JE } \\
\text { (a) }\end{array}$ & $\begin{array}{l}\text { No. of anti-JEV } \\
\text { IgM positive cases } \\
\text { (b) }\end{array}$ & $\begin{array}{l}\text { Positive rate } \\
(\mathrm{b} / \mathrm{a} \times 100) \\
(\%)\end{array}$ \\
\hline $\begin{array}{l}\text { Nepalgunj Medical } \\
\text { College Hospital }\end{array}$ & 9 & 7 & 78 \\
Bardia District Hospital & 14 & 13 & 93 \\
Bheri Zonal Hospital & 30 & 21 & 70 \\
Total & 53 & 41 & 77 \\
\hline \hline
\end{tabular}

Table 4. JE incidence ratio (per 1000) according to the number of VDC* in three districts of western part of Nepal in 1997

\begin{tabular}{|c|c|c|c|c|c|c|}
\hline \multirow[b]{2}{*}{$\begin{array}{l}\text { Incidence ratio } \\
\text { (per 1000) }\end{array}$} & \multicolumn{2}{|l|}{ Banke } & \multicolumn{2}{|l|}{ Bardia } & \multicolumn{2}{|l|}{ Kailali } \\
\hline & $\begin{array}{l}\text { No. of } \\
\text { VDC }\end{array}$ & $(\%)$ & $\begin{array}{l}\text { No. of } \\
\text { VDC }\end{array}$ & $(\%)$ & $\begin{array}{l}\text { No. of } \\
\text { VDC }\end{array}$ & $(\%)$ \\
\hline$R \leqslant 1 \cdot 0$ & 36 & 77 & 9 & 27 & 17 & 38 \\
\hline $1 \cdot 0<\mathrm{R} \leqslant 2 \cdot 0$ & 7 & 17 & 12 & 36 & 15 & 33 \\
\hline $2 \cdot 0<\mathrm{R} \leqslant 3 \cdot 0$ & 3 & 4 & 11 & 33 & 11 & 25 \\
\hline $3 \cdot 0<$ & 1 & 2 & 1 & 3 & 2 & 4 \\
\hline Total & 47 & 100 & 33 & 100 & 45 & 100 \\
\hline
\end{tabular}

* VDC, Village Development Committee (the minimum administrative unit).

incidence ratio was over $2 \cdot 0 / 1000$ among approximately $30 \%$ of VDCs in Bardia and Kailali (Bardia $36 \%$, Kailali $29 \%$ ). These results demonstrate that the higher JE incidence was clustering around the National Park in Bardia and the south-east area (around Tikapur VDC) in Kailali (Fig. 3).

\section{DISCUSSION}

Usually health facilities in Nepal have JE record books. Those are used for reporting JE cases to health authorities and total number of JE cases in 1997 was 2408 [8]. The number we could review in those record books in study area was 1819 . It means our study could cover $75.7 \%$ of the total JE reported cases in Nepal in 1997. Therefore, results of the study would reflect the features of JE status in this country. One interesting result of the present study was high level of clustering of JE cases in the western part of Nepal. This was revealed by the mapping of cases. The average $\mathrm{JE}$ incidence ratio in the three regions was $1 \cdot 4 / 1000$ and highest value was $1 \cdot 8 / 1000$ in the Bardia district. Approximately, one-quarter of the VDCs (29 among 123) in the study area showed incidence ratio equal to or greater than $2 \cdot 0 / 1000$. JE symptoms are manifested usually in one among 200-500 infected cases [2]. If we estimate that one among 500 infected cases shows JE clinical sign (i.e. 2·0/1000 incidence ratio), quite a large number of inhabitants of VDC in the western part of Terai were infected by JE virus. The estimated population of VDC with an infection ratio of 2.0/1000 was 342174 (District Public Health Office Annual Report for 1997, Ministry of Health, Nepal) and the total estimated population in three districts was 1228223. Simple calculation revealed that $27.9 \%$ of the entire inhabitants in the study area were infected by JE virus during the 4 months' JE epidemic (Fig. 2). The highest incidence ratio was observed in VDC inside the along the forest of National Park. It was recognized that patients were taken to health facilities at very late stages of JE. Most were already unconscious on admission. Our interviews with the village people also found that the first choice of health facility for the majority of people was the traditional faith healers as a health care provider. This attitude was prominent among relatively poor ethnic group, e.g. Tharu. Thus, it is likely that actual percentage of JEV infection could be much higher and a more serious JE epidemic existed in these communities.

The scourge of JE predominantly affected females under 5 years of age. Admission rate in female was far 


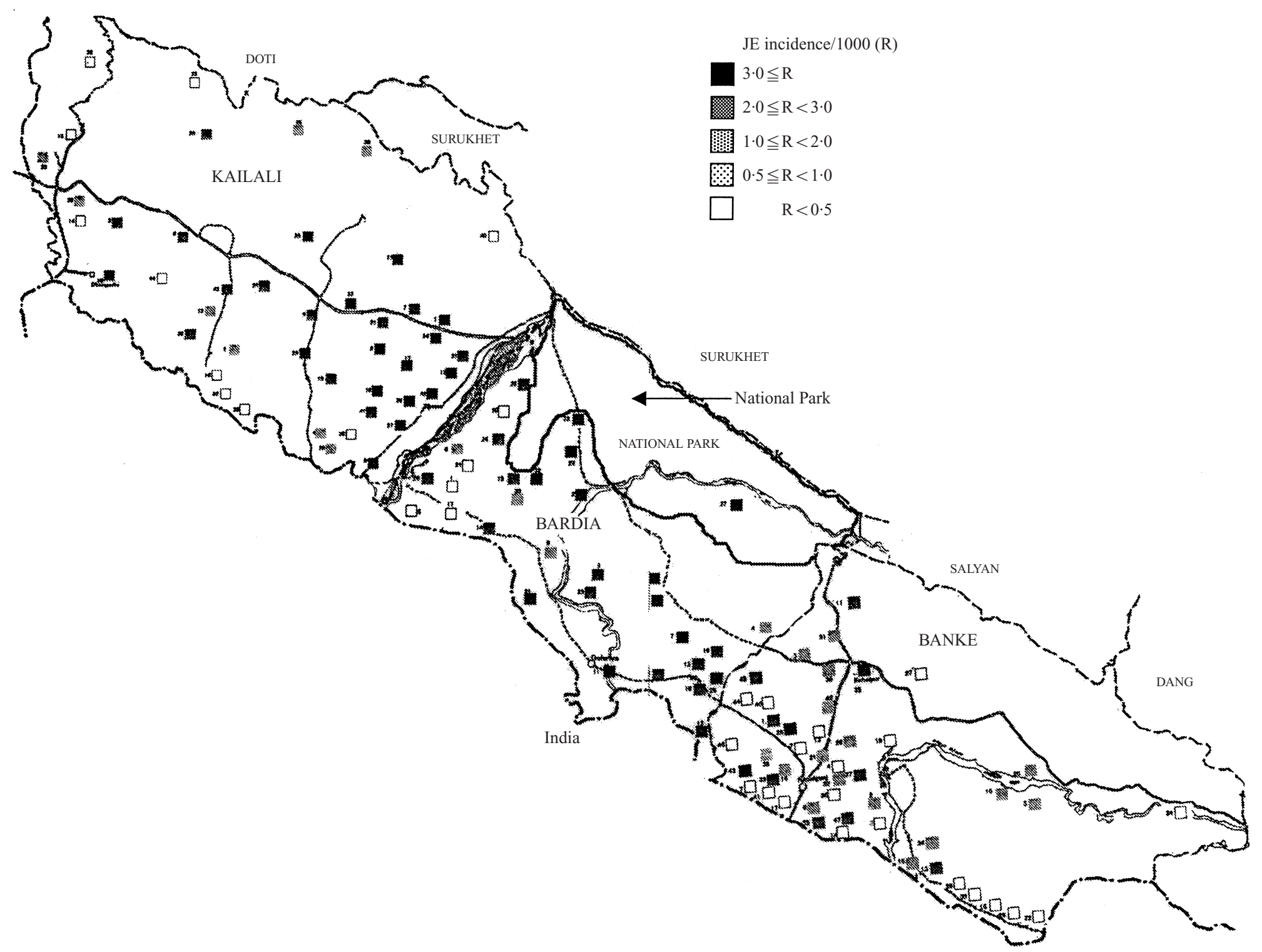


lower than in male in this group ( $70 \%$ less than male). Furthermore, the fatality rate among female children was more than two times higher than male children of the same age group. There is no evidence of a difference in JE susceptibility between male and female. Thus, this phenomenon may be attributed to gender discrimination. Generally, Nepali consider males as more important than females. For example, the literacy rate of females is significantly lower than that of males (females $45.5 \% \mathrm{vs}$. males $74.3 \%$ ) [18] and this attitude is more prominent in rural areas. With regards to the mortality rate between males and females, females are more likely to die than male (1.4 vs. 1.0) [17]. This evidence may support gender discrimination against young female JE patients.

The validity of JE diagnosis is sometimes questioned in developing countries without JE-specific laboratory examinations. The earliest symptoms of JE are lethargy, nausea, neck rigidity, abdominal pain and abrupt fever. It is well known that these clinical manifestations are common with pyogenic meningitis, typhoid fever, cerebral malaria, dengue, measles, enterovirus and other infectious diseases. Non-infectious causes, i.e. heat stroke, vascular occlusion, acute electrolyte disturbance also manifest encephalitis-like symptoms $[19,20]$. Kumar reported that the $\mathrm{JE}$ virus contribution to acute encephalitis was $23 \%$ in India [21]. However, JE-specific IgM study in Nepal revealed that JE diagnosis in the monsoon season was rather accurate. Bardia District Hospital demonstrated a $93 \%$ accuracy of JE diagnosis with the use of an exclusion test to distinguish JE from malaria, typhoid and pyogenic meningitis. Although the other two health facilities did not routinely perform the exclusion tests, the JE diagnosis was fairly reliable. Thus, it is likely that promoting the use of JE exclusion tests will improve the accuracy of JE diagnosis in those health facilities and it will be applicable to all hospitals in Nepal.

JE control in Nepal is not an easy task. JE-specific IgM ELISA showed that JE diagnosis is fairly reliable and monsoon encephalitis could be attributed to JE. However, even though patients are accurately diagnosed as JE, there is no specific treatment and only supportive care (e.g. control of fever, attention to fluid balance, etc) is available. In this context, the prevention of JE infection is the most effective countermeasure. Many actions have been taken in epidemic areas in Nepal. This survey identified that numbers of pigs (JEV amplifier) were dramatically reduced through health education and people's fear of JE in the epidemic areas. However, people still keep pigs for their income and there are no control measures for the tremendous numbers of wild marshy birds which are JEV amplifiers as well. Prevalence of mosquito nets is still low due to their relatively high price. Reduction of mosquito numbers is virtually impossible in Nepal in view of the high price of insecticides and vast area of rice fields where mosquitoes breed.

Under these circumstances, JE vaccine is the most effective countermeasure for JE control in Nepal. Epidemiological studies have demonstrated the efficacy and safety of JE vaccine [22,23] and is widely applied to people living in or travelling in JE epidemic areas. One of the problems of currently available JE vaccine is the high price. Formalin-inactivated JE vaccine costs $\$ 2 \cdot 16-3 \cdot 68$ for one shot [6]. The general use of this vaccine is not possible in such a resourcescarce country like Nepal (GNP per capita: \$230). In view of the expansion of the JE scourge in developing countries, development of a safer and affordable JE vaccine needs to be promoted so that the disastrous JE situation can be mitigated.

\section{ACKNOWLEDGEMENTS}

The authors would like to thank Dr Alison Cravan, International Nepal Fellowship, for her all support in Nepal and Mr R. P. S. Sedhain for his kind assistance to this study.

\section{REFERENCE}

1. Umenai T, Krzysko R, Bektiminov A, Assaad F. Japanese encephalitis - current worldwide status. Bull WHO 1985; 63: 625-31.

2. Tsai TF Japanese encephalitis. In: Feigin RD Cherry GM. Textbook of pediatric infectious diseases 4th edn. Philadelphia: Saunders, 1995: 1997.

3. Hanna JN, Ritchie SA, Phillips DA, et al. Japanese encephalitis in north Queensland, Australia, 1998. Med J Aust 1999; 170: 533-6.

4. Paul WS, Moore PS, Karabatsos N, et al. Outbreak of Japanese encephalitis on the island of Saipan, 1990. J Infect Dis 1993; 167: 1053-8.

5. Wada Y. Control of Japanese encephalitis vectors. Species complex of the vectors. Southeast Asian J Trop Med Publ Hlth 1989; 20: 623-5.

6. Siraprapasiri T, Sawaddiwudhipong W, Rojanasuphot S. Cost benefit analysis of Japanese encephalitis vaccination programme in Thailand. Southeast Asian J Trop Med Publ Hlth 1997; 28: 143-8.

7. Hoke CH, Vaughn DW, Nisalak A, et al. Effect of highdose dexamethasone on the outcome of acute encephalitis virus. J Infect Dis 1992; 165: 631-7.

8. Prahan SP. Trend of case incidence and case fatality 
rate of Japanese encephalitis in Nepal - Period 1978-1997, Consultant Report for the Ministry of Health, Nepal, 1997.

9. Joshi DD, Gaidamovich S. Serological surveillance of virus encephalitis in Nepal. Bull Vet Soc Anim Hlth, Nepal 1982: 8-12.

10. Wakai S. Scourge of Japanese encephalitis in southwestern Nepal. Lancet 1998; 351: 759.

11. Parajuli MB, Joshi DD, Pradan SP, Chamling M, Joshi AB. Incidence of Japanese encephalitis during 1989 in Nepal. J Nepal Med Assoc 1992; 30: 7-14.

12. Kudo T, Rai SK, Rawal S, Yamano T. Serological study of Japanese encephalitis in Nepal. Southeast Asian J Trop Med Publ Hlth 1993; 24: 756-61.

13. Department of Hydrology \& Meteorology, Ministry of Science and Technology, Preliminary Monthly Weather Summary of Nepal 1997, 1998.

14. Duermeyer W, Wielaard F, van der Veen J. A new principle for the detection of specific IgM antibodies applied in an ELISA for hepatitis. A J Med Virol 1979; 4: 25-32.

15. Igarashi A, Bundo K, Matsuo S, Makino Y, Lin WJ. Enzyme-linked immunosorbent assay (ELISA) on Japanese encephalitis virus. I. Basic conditions of the assay on human immunoglobulin. Trop Med 1981; 23: 45-59.
16. Burke DS, Nisalak A, Ussery MA. Antibody capture immunoassay detection of Japanese encephalitis virus immunoglobulin $\mathrm{M}$ and $\mathrm{G}$ antibodies in cerebrospinal fluid. J Clin Microbiol 1982; 16: 1034-42.

17. United Nations Population Fund. Atlas of Population Distribution and Health Facilities in Nepal, Katmandu, 1994: UNFPA.

18. Nepal Human Development Report. Nepal South Asia Centre, Kathmandu, 1998 Nepal, 1998, UNDP.

19. Tsai TF, Yu. YX. Japanese encephalitis vaccine. In: Plotkin SA, Mortimer EA, Vaccines 2nd edn, Philadelphia: Saunders, 1994: 673.

20. Thongcharoen P. Japanese encephalitis: an overview. Southeast Asian J Trop Med Publ Hlth 1989; 20: 559-73.

21. Kumar R, Mathur A, Kumar A, et al. Virological investigations of acute encephalopathy in India. Ind Council Med Res 1990; 95: 1238-1230.

22. Hoke CH, Nisalak A, Sangawhipa N, et al. Protection against Japanese encephalitis by inactivated vaccine. $\mathrm{N}$ Engl J Med 1989; 319: 609-14.

23. Gambel JM, DeFraites R, Hoke C, et al. Japanese encephalitis vaccine: persistence of antibody up to 3 years after a three-dose primary series. J Infect Dis 1995; 171: 1074. 